\title{
Article
}

\section{Effects of specific and non-specific court footwear on anterior cruciate ligament loading during a maximal change of direction manoeuvre}

Sinclair, Jonathan Kenneth and Stainton, Philip

Available at http://clok.uclan.ac.uk/19303/

Sinclair, Jonathan Kenneth ORCID: 0000-0002-2231-3732 and Stainton, Philip (2017) Effects of specific and non-specific court footwear on anterior cruciate ligament loading during a maximal change of direction manoeuvre. Footwear Science. pp. 1-7. ISSN 1942-4280

It is advisable to refer to the publisher's version if you intend to cite from the work. http://dx.doi.org/10.1080/19424280.2017.1363822

For more information about UCLan's research in this area go to http://www.uclan.ac.uk/researchgroups/ and search for <name of research Group>.

For information about Research generally at UCLan please go to http://www.uclan.ac.uk/research/

All outputs in CLoK are protected by Intellectual Property Rights law, including Copyright law. Copyright, IPR and Moral Rights for the works on this site are retained by the individual authors and/or other copyright owners. Terms and conditions for use of this material are defined in the policies page. 


\section{during a maximal change of direction manoeuvre.}

3 Word count: 3450

4 Key words: Biomechanics, anterior cruciate ligament, sports, footwear, injury.

6 Abstract

7 The aim of the current investigation was to examine the effects of tennis shoes and running footwear on the loads experienced by the ACL during a maximal change of direction task.

9 Thirteen male participants performed maximal change of direction movements in tennis

shoes and running footwear. Lower limb kinematics were collected using an 8 camera motion

11 capture system and ground reaction forces were quantified using an embedded force

12 platform. Anterior cruciate ligament (ACL) loading was examined via a musculoskeletal modelling approach and the frictional properties of the footwear were examined using ground

14 reaction force information. Differences in ACL loading parameters between footwear were examined using one-way repeated measures ANOVA and multiple regression analyses were used to determine frictional predictors of ACL loading. Peak ACL force was significantly larger in the tennis shoes $(2308.35 \mathrm{~N})$ in relation to running footwear $(1859.21 \mathrm{~N})$ conditions. In addition, it was shown that the peak rotational moment was a significant predictor of peak ACL force in the tennis shoes (Adjusted $\mathrm{R}^{2}=0.68$ ) and running footwear (Adjusted $\mathrm{R}^{2}=$ 0.61) conditions. The findings from the current investigation indicate that the specific tennis shoes examined in the current investigation may place athletes at increased risk from ACL 
substantiated.

\section{Introduction}

Racquet court sports such as tennis are associated with repeated high-intensity, intermittent movement bouts, with rallies of between 5-20 seconds (Fernandez et al., 2006). Whilst biomechanical literature has predominantly focussed on linear running, this mode of locomotion is not ecologically relevant to the majority of sporting movements, particularly in court sports (Lees, 2003). Court sports such as tennis require players to perform an array of

different movements including jumping, and rapid changes of direction/ cutting manoeuvres

(Hewit et al., 2013). The ability to quickly change direction is important for effective

performance in racquet court sports, allowing players more time to execute their strokes and providing a mechanism to gain positional advantage on the court (Baker \& Newton, 2008).

Tennis is associated with a high rate of knee pathologies in relation to other athletic disciplines, with the anterior cruciate ligament (ACL) accounting for $11 \%$ of all knee injuries (Majewski et al., 2006). ACL injuries are extremely serious and can lead to long term

40 absence from competitive sport (Olsen et al., 2004). ACL injuries typically lead to long term

41 discomfort at the knee, which forces many athletes to permanently withdraw from training/

42 competition. Indeed, Roos et al., (1995) demonstrated that only $30 \%$ of competitive 43 footballers remained active 3 years after suffering an ACL injury. Even after full 44 physiological recovery from ACL injury, athletes typically fail to return to their previous 
45 levels of function, as statistically significant performance decrements have been observed in relation to non-injured controls (Carey et al., 2006).

In addition, athletes who experience an ACL pathology are statistically more likely to experience degenerative knee osteoarthritis in relation to non-injured controls (Øiestad et al., 2009). Thus experiencing an ACL injury serves to reduce engagement with sport/ physical activity but also leads to chronic pain and disability in later life (Ajuied et al., 2014). In the US alone over 175,000 ACL reconstruction surgeries are conducted annually, with directly associated costs in excess of over \$2 billion and total allocated costs of \$3.4 billion (Gottlob et al., 1999).

Injuries to the ACL are predominantly non-contact in nature, in that the ligament is damaged without any physical interaction between athletes (Boden et al., 2009). ACL pathologies occur mechanically when excessive loading is experienced by the ligament itself (Smith et al., 2012). Non-contact ACL pathologies typically involve decelerations, cutting movements, sudden changes of direction, or landings from a jump (Olsen et al., 2004). Athletes are particularly at risk when the foot is in an everted closed-chain position at footstrike, the tibia is rotated internally, and the knee is minimally flexed (Shimokochi \& Shultz, 2008).

Like all footwear, tennis shoes are designed in order to improve performance and to attenuate

injury. The mechanical characteristics of tennis shoes are traditionally designed specifically 
outsole-surface interface is important to reduce undesirable levels of movement of the shoe relative to the surface (Carre et al., 2014). The frictional properties of athletic footwear are typically investigated in biomechanical analyses using both the peak translational coefficient of friction and rotational friction moment (Frederick, 1993). In tennis in particular, the frictional characteristics of sports footwear can affect both performance and the risk of injury (Frederick, 1993). Excessive friction can lead to injury due to overloading of the soft tissues in the lower extremities (Thomson et al., 2015), whereas insufficient friction can cause excessive foot motion relative to the surface, which causes decrements in performance (Frederick, 1993).

Tennis players typically wear either court specific footwear or running shoes, however tennis footwear has received relatively little attention in biomechanical literature. Luethi et al., (1986) investigated the effects of tennis shoes with flexible and stiff midsoles, during a lateral hopping task. Their results indicated that the flexible footwear condition was associated with significantly larger peak vertical impact forces and peak angles of foot inversion. Strauss et al., (2009) explored the effects of multi-court, hard, grass and clay court specific tennis footwear during a running forehand drive, on hard, grass and clay surfaces. Their findings showed that on a hard court the specific footwear reduced the vertical load rate in comparison to the multi-court footwear. Conversely on the grass court, the specific footwear increased the vertical load rate in comparison to the multi-court footwear. Herbaut et al., (2015) identified the effects tennis shoe drop on the kinetics and kinematics of junior tennis players during an open-stance forehand. Their results indicated that the lower drop footwear condition was associated with a reduced vertical impact peak and also a less dorsiflexed ankle angle at the instance of foot contact. Finally, Sinclair, (2017) examined the effects of court specific, minimalist and running trainers during a change of direction task. The findings showed that 
the instantaneous load rate and peak tibial accelerations were significantly larger in the

94

95

96

97

98

99

100

101

102

103

104

105

106

107

108

109

110

111

112

113

114

minimalist and court specific footwear compared with the running trainers. In addition, the

peak angle of inversion was revealed to be significantly larger in the minimalist compared to the court footwear and running trainers. However, there is currently no quantitative information relating to the effects of tennis footwear on the loads experienced by the ACL during change of direction movements.

Therefore, the aim of the current investigation was to examine the effects of tennis shoes and running footwear on the loads experienced by the ACL during a maximal change of direction task. Research of this nature may provide important new information to athletes regarding the selection of appropriate footwear for the prevention of ACL injuries during tennis based activities.

\section{Methods}

\section{Participants}

Thirteen male court athletes volunteered to take part in this study. The mean characteristics of the participants were: age $23.15 \pm 2.66$ years, height $177.91 \pm 4.55 \mathrm{~cm}$ and body mass $75.11 \pm$ $5.74 \mathrm{~kg}$. All were free from lower extremity pathology at the time of data collection and provided written informed consent. The procedure was approved by a University ethics committee STEMH 512.

Experimental footwear 
The footwear used during this study consisted of, running footwear (New Balance $1260 \mathrm{v} 2$ ),

and tennis shoes (Hi-Tec Indoor Lite) (shoe size 8-10 in UK men's sizes) (Figure 1). The

running footwear had an average mass of $0.285 \mathrm{~kg}$, heel thickness of $25 \mathrm{~mm}$ and a heel drop

of $14 \mathrm{~mm}$. The running footwear tread pattern was a mixture of circular and elliptical grooves

with a discontinuity between the rear and forefoot components. Whereas the tennis shoes had

an average mass of $0.368 \mathrm{~kg}$, heel thickness of $28 \mathrm{~mm}$ and a heel drop of $10 \mathrm{~mm}$. The tennis

shoes tread pattern was predominantly a curved herringbone configuration and also had

discontinuity between the rear and forefoot components.

@@@ FIGURE 1 NEAR HERE @@@

Participants were instructed to perform maximal $180^{\circ}$ cutting manoeuvres whilst striking an embedded force platform (Kistler, Kistler Instruments Ltd., Alton, Hampshire; length, width, height $=0.6 \times 0.4 \times 0 \mathrm{~m}$ ) with their right (dominant foot) foot. The force platform sampled at $1000 \mathrm{~Hz}$. Participants commenced their trials from $6 \mathrm{~m}$ away from the force platform. This distance was selected as being approximately half the width of a tennis court and was deemed to be typical of the distances that tennis players may be expected to run and then change direction (Sinclair, 2017). Participants ran straight ahead for $6 \mathrm{~m}$ then planted their dominant foot on the force plate, and then changed direction to move $180^{\circ}$ to their initial direction of motion. The stance phase was delineated as the duration over which $>20 \mathrm{~N}$ of vertical force was applied to the force platform (Sinclair et al, 2011). 
platform. Five successful trials were obtained in each footwear condition. A successful trial was defined as one in which the foot made full contact with the force platform and there was no evidence of gait modifications due to the experimental conditions. The order in which participants performed in each footwear condition was counterbalanced. To ensure that participants utilized a similar approach velocity in each of the experimental footwear; the linear velocity of the pelvic segment was quantified. The approach velocity during the first trial was calculated and a maximum deviation of $5 \%$ from this velocity was allowed throughout data collection for each participant.

Kinematics and ground reaction force information were synchronously collected. Kinematic data were captured at $250 \mathrm{~Hz}$ via an eight camera motion analysis system (Qualisys Medical AB, Goteburg, Sweden). Lower extremity segments were modelled in 6 degrees of freedom using the calibrated anatomical systems technique (Cappozzo et al., 1995). To define the segment co-ordinate axes of the right foot, shank and thigh, retroreflective markers were placed unilaterally onto the 1 st metatarsal, 5th metatarsal, calcaneus, medial and lateral malleoli, medial and lateral epicondyles of the femur. To define the pelvis segment further markers were positioned onto the anterior (ASIS) and posterior (PSIS) superior iliac spines. Carbon fiber tracking clusters were positioned onto the shank and thigh segments. The foot was tracked using the 1st metatarsal, 5th metatarsal and calcaneus markers and the pelvis using the ASIS and PSIS markers. The centers of the ankle and knee joints were delineated as the mid-point between the malleoli and femoral epicondyle markers, whereas the hip joint centre was obtained using the positions of the ASIS markers. This method placed the hip joint centre $14 \%$ of the ASIS breadth medially, $19 \%$ posteriorly, and $30 \%$ distally from the ipsilateral (Right) ASIS (Bell et al., 1999). Static calibration trials were obtained in each footwear allowing for the anatomical markers to be referenced in relation to the tracking 
markers/ clusters. The Z (transverse) plane was oriented vertically from the distal segment end to the proximal segment end. The Y (coronal) plane was oriented in the segment from posterior to anterior. Finally, the $\mathrm{X}$ (sagittal) plane orientation was determined using the right hand rule and was oriented from medial to lateral.

Processing

Dynamic trials were digitized using Qualisys Track Manager in order to identify anatomical and tracking markers then exported as C3D files to Visual 3D (C-Motion, Germantown, MD, USA). Ground reaction force and kinematic data were smoothed using cut-off frequencies of 25 and $12 \mathrm{~Hz}$ with a low-pass Butterworth 4th order zero lag filter. Euler knee joint angles were calculated using an XYZ sequence of rotations and knee joint moments were calculated using Newton-euler inverse dynamics within Visual 3D.

A musculoskeletal modelling approach was utilized to quantify ACL loading, as described and validated by Dai \& Yu, (2012). This approach has been shown to be sufficiently sensitive to resolve differences in ACL force during different movements (Dai \& Yu, 2012) and also as a function of different prophylactic mechanisms (Sinclair \& Taylor, 2017). The face validity of the current model has been evaluated from three key aspects in the literature. Firstly, Dai \& Yu, (2012) showed that the model exhibited a high level of consistency with the values provided from in vivo ACL loading investigations (Cerulli et al., 2003; Taylor et al., 2011). Secondly, the timing of ACL injuries in dynamic tasks occurs within the first $50 \mathrm{~ms}$ after the initial foot contact (Krosshaug et al., 2007). The timing of the peak ACL force estimated using this model by both Dai \& Yu, (2012) and Sinclair et al., (2017) was shown to be < 50 
ms, which is consistent with this data and supports the face validity of the model. Thirdly

Brown et al., (2012) demonstrated that landing with increased knee flexion reduced in vivo peak ACL loading. The data provided by Dai \& Yu, (2012) supported this notion as they showed that peak ACL force was greater when landing with reduced knee flexion.

Firstly, the tibia-anterior shear force (TASF) was calculated, which was undertaken using a modified version of the model described in detail by Devita \& Hortobagyi, (2001). Our model differed only in that gender specific estimates of posterior tibial plateau slope (Hohmann et al., 2011), hamstring-tibia shaft angle (Lin et al., 2009) and patellar tendon-tibia shaft angle (Nunley et al., 2003) were utilized.

ACL loading was determined in accordance with the below equation. Key input parameters into this model where TASF, transverse plane knee moment, coronal plane knee moment and also in vitro information based on the data of Markolf et al., (1995), which were extrapolated as a function of the knee flexion angle measured during the current study. The first component $(F 100)$ of the above equation was mediated via by the TASF. ACL forces caused by a $100 \mathrm{~N}$ TASF at different knee angles were obtained by digitizing and fitting a polynomial curve to the data described by Markolf et al., (1995), who examined ACL forces in vitro when a $100 \mathrm{~N}$ TASF was applied to cadaver knees from $0-90^{\circ}$ of knee flexion. $F 100$ was extrapolated using the knee flexion data from the current investigation. The second component (F10TV) was caused by the knee transverse plane moment. The ACL forces caused by a $10 \mathrm{Nm}$ transverse plane knee moment, across the different knee angles were obtained by digitizing and fitting a polynomial curve to the data of Markolf et al. (1995). F10TV was similarly extrapolated as a function of the knee flexion data from the current 
investigation. The final aspect $(F 10 C R)$ was caused by the knee coronal plane moment. The

212 ACL forces caused by a $10 \mathrm{Nm}$ coronal plane knee moment, across the different knee angles

were again obtained by digitizing the data reported by Markolf et al. (1995). F10CR was

214

extrapolated using the knee flexion data from the current investigation.

215

216

ACL load $=(F 100 / 100 *$ TASF $)+(F 10 T V / 10 *$ transverse plane knee moment $)+(F 10 C R$

/ $10 *$ coronal plane knee moment)

218

219

From the musculoskeletal model, peak ACL force (N) was extracted. In addition, ACL

average (N/s) and instantaneous load rates (N/s) were quantified. Average load rate was

221

obtained by dividing the peak ACL force by the duration over which the peak force occurred

222

and instantaneous load rate was quantified as the peak increase in force between adjacent data

223

points. Finally, ACL impulse $(\mathrm{N} \cdot \mathrm{s})$ during the stance phase was quantified using a trapezoidal

224

function.

225

226 In addition, the peak translation coefficient of friction $(\mu)$ of each footwear was determined

227 from the ratio of horizontal and vertical force components during the initial period of

228 shoe motion (Stiles \& Dixon, 2006). The peak rotational moment of the ground reaction force

229

(Nm) was used to describe the rotational friction characteristics of the footwear (Holden \&

230

Cavanagh, 1991).

231

232

Statistical analyses 
233 Means, standard deviations (SD) and $95 \%$ confidence intervals (95\% CI) were calculated for

234 each outcome measure for both footwear conditions. Differences in ACL loading parameters

235 between footwear were examined using one-way repeated measures ANOVAs. Effect sizes

236 were calculated using partial eta ${ }^{2}\left(\mathrm{p \eta}^{2}\right)$. The data was screened for normality using a Shapiro-

237 Wilk which confirmed that the normality assumption was met. In addition, multiple 238 regression analyses with peak ACL force as criterion and peak translation coefficient of 239 friction and peak rotational moment as predictor variables were conducted for each footwear 240 condition using a forward stepwise procedure. An alpha level of $\mathrm{P} \leq 0.05$ was used 241 throughout as the criterion for statistical significance (Sinclair et al., 2013), and statistical 242 actions were conducted using SPSS v23.0 (SPSS Inc., Chicago, USA).

\section{$244 \quad$ Results}

Tables 1-2 and figure 2 present the ACL loading parameters that were obtained as a function of the different footwear conditions examined as part of this investigation.

247

It was revealed that peak ACL force was significantly $\left(P=0.009, \mathrm{p}^{2}=0.55\right)$ larger in the 
larger in the tennis shoes compared to the running footwear.

257

Peak rotational moment was significantly $\left(P=0.003, \mathrm{p}^{2}=0.64\right)$ larger in the tennis shoes in relation running footwear. In addition, peak translational coefficient of friction was significantly $\left(\mathrm{P}=0.003, \mathrm{p}^{2}=0.63\right)$ greater in the running footwear in relation to the tennis shoes.

Regression analyses

The multiple regression analyses showed that for the tennis shoes (Adjusted $\mathrm{R}^{2}=0.68, \mathrm{P}<$ 0.05 ), and running footwear (Adjusted $\left.\mathrm{R}^{2}=0.61, \mathrm{P}<0.05\right)$ the peak rotational moment was a significant predictor of peak ACL force.

\section{Discussion}

272 The aim of the current investigation was to examine the effects of tennis shoes and running

273 footwear on the loads experienced by the ACL during a maximal effort change of direction

274 task. To the authors knowledge this represents the first comparative investigation to quantify 275 the effects of different tennis footwear on ACL loading during a change of direction 
movement. Quantitatively investigating the parameters linked to the aetiology of ACL injury may provide tennis players with key clinical information regarding the selection of appropriate footwear for their training/ competition.

Importantly the current investigation showed that ACL loading parameters were significantly greater in the tennis shoes in relation to the running footwear. The mechanical aetiology of ACL injury in athletic populations is caused by excessive loading of the ACL itself (Smith et al., 2012). ACL injuries are considered to be extremely serious and habitually require reconstructive intervention leading to long term absences from competition (Myklebust \& Bahr, 2004). Therefore, given the statistical increases in ACL loading in the tennis shoes, the results from the current observation may be clinically relevant for tennis based athletes. It can be conjectured based on the findings from this investigation that the specific tennis shoes examined in this investigation may increase the risk from ACL injury during sport specific change of direction movements.

In addition, it was also revealed that the tennis shoes were statistically associated with the highest values for the peak rotational moment and the lowest values for the peak translational coefficient of friction in relation to the running footwear. A likely explanation for this observation is based on the tread patterns of each shoe outsole which are distinct between the three footwear examined as part of the current study (Figure 1) (Valiant et al., 1985). This observation concurs with the observations of Severn, et al., (2011) and Wannop \& Stefanyshyn, (2015) which indicates that manipulating the outsole patterns of different footwear can alter both rotational and translational friction characteristics. 
300 It also appears based on the findings from the current analysis that the tennis shoes were effective in enhancing rotational friction but not optimal in promoting translational friction. The frictional properties between the shoe and surface are an important determinant of athletic performance, but high levels of friction at the outsole-surface interface may also be related to increased risk of soft tissue injury (Wannop et al., 2009). There is currently no agreement regarding the optimal frictional values that are required to provide sufficient traction, but also attenuate risk from injury during sports movements (Frederick, 1993). Importantly the current investigation showed that the rotational friction moment as opposed to the translational coefficient of friction was a significant predictor of the peak ACL force in all of the experimental footwear. This supports the proposition of Thomson et al., (2015) and indicates that during maximal change of direction tasks the peak rotational moment is the most clinically meaningful frictional parameter in relation to the development and prevention of ACL pathologies.

A potential limitation to the current analysis is that ACL loading parameters were quantified using a musculoskeletal modelling approach. This was a requirement of the current investigation given the impracticalities of obtaining in vivo measures of ligament loading during dynamic movements. Although the current model has been shown to exhibit good face validity (Dai \& Yu, 2012), musculoskeletal models by definition are always subject to some mathematical assumptions that may compromise their efficacy across a range of participants. A further potential drawback is the laboratory based nature of the data collection protocol. Specifically, the stiffness and frictional properties of the laboratory surface are likely to be 
measures design and thereby the statistical comparison between footwear is sound, as

participants performed in the same conditions in both footwear. However, the ecological

validity of the procedure from a practical context was compromised as ACL loading may

have differed had participants performed on a tennis specific surface. Therefore, it is strongly

recommended that the current investigation be repeated using a field based data collection

protocol.

In conclusion; although the biomechanical effects of tennis shoes have been examined previously; current knowledge regarding differences in ACL loading when performing change of direction tasks is limited. The current investigation thus adds to the current literature base by performing a comprehensive evaluation of ACL loading parameters when performing a change of direction task in tennis shoes and running footwear. Importantly, the current study showed ACL loading parameters were significantly greater in tennis shoes in relation to the running footwear. The findings from the current investigation indicate that the specific tennis shoes examined as part of this investigation may place athletes who undertake

court based activities at increased risk from ACL pathology during maximal change of

directions movements. However, further exploration using a more ecologically valid research

design is required before this notion can be truly substantiated.

\section{References}

1. Ajuied, A., Wong, F., Smith, C., Norris, M., Earnshaw, P., Back, D., \& Davies, A. 
osteoarthritis: a systematic review and meta-analysis. The American Journal of Sports Medicine, 42, 2242-2252.

2. Baker, D.G., \& Newton, R.U. (2008). Comparison of lower body strength, power, acceleration, speed, agility, and sprint momentum to describe and compare playing rank among professional rugby league players. Journal of Strength and Conditioning Research, 22, 153-158.

\section{Bell, A.L., Brand, R.A., \& Pedersen, D.R. (1999). Prediction of hip joint centre} location from external landmarks. Human Movement Science, 8, 3-16.

4. Boden, B.P., Torg, J.S., Knowles, S.B., \& Hewett, T.E. (2009). Video analysis of anterior cruciate ligament injury abnormalities in hip and ankle kinematics. The American Journal of Sports Medicine, 37, 252-259.

5. Cappozzo A., Catani F., Leardini A., Benedeti M.G., \& Della Croce, U. (1995). Position and orientation in space of bones during movement: Anatomical frame definition and determination. Clinical Biomechanics, 10, 171-178.

6. Carey, J. L., Huffman, G. R., Parekh, S. G., \& Sennett, B. J. (2006). Outcomes of anterior cruciate ligament injuries to running backs and wide receivers in the National Football League. The American journal of sports medicine, 34, 1911-1917.

7. Carré, M.J., Clarke, J.D., Damm, L., \& Dixon, S.J. (2014). Friction at the tennis shoecourt interface: how biomechanically informed lab-based testing can enhance understanding. Procedia Engineering, 72, 883-888.

8. Dai, B, \& Yu, B. (2012). Estimating ACL force from lower extremity kinematics and kinetics. 36th annual meeting of the American Society of Biomechanics Gainesville, Florida, 253-254. 
9. DeVita, P., \& Hortobagyi, T. (2001). Functional knee brace alters predicted knee muscle and joint forces in people with ACL reconstruction during walking. Journal of Applied Biomechanics, 17, 297-311.

10. Fernandez, J., Mendez-Villanueva, A., \& Pluim, B.M. (2006). Intensity of tennis match play. British Journal of Sports Medicine, 40, 387-391.

11. Finch, C., \& Eime, R. (2001). The epidemiology of squash injuries. International Journal of Sports Medicine, 2, 1-11.

12. Frederick, E. C. (1993). Optimal frictional properties for sport shoes and sport surfaces. In ISBS Conference Proceedings Archive.

13. Gottlob, C.A., Baker, C.L., Pellissier, J.M., \& Colvin, L. (1999). Cost effectiveness of anterior cruciate ligament reconstruction in young adults. Clinical Orthopaedics and Related Research, 367, 272-282.

14. Herbaut, A., Simoneau, E., Barbier, F., Roux, M., Guéguen, N., \& Chavet, P. (2015) Lower shoe drop can reduce impact forces experienced by junior tennis players performing an open-stance forehand. Footwear Science, 7, 112-113.

15. Hewit, J.K., Cronin, J.B., \& Hume, P.A. (2013). Kinematic factors affecting fast and slow straight and change-of-direction acceleration times. The Journal of Strength \& Conditioning Research, 27, 69-75.

16. Holden, J.P., \& Cavanagh, P.R. (1991). The free moment of ground reaction in distance running and its changes with pronation. Journal of Biomechanics, 24, 891897.

17. Hohmann, E., Bryant, A., Reaburn, P., \& Tetsworth, K. (2011). Is there a correlation between posterior tibial slope and non-contact anterior cruciate ligament injuries?. Knee Surgery, Sports Traumatology, Arthroscopy, 19, 109-114. 
18. Lees, A. (2003). Science and the major racket sports: a review. Journal of sports sciences, 21, 707-732.

19. Lim, B.O., Lee, Y.S., Kim, J.G., An, K.O., Yoo, J., \& Kwon, Y.H. (2009). Effects of sports injury prevention training on the biomechanical risk factors of anterior cruciate ligament injury in high school female basketball players. The American Journal of Sports Medicine, 37, 1728-1734.

\section{Luethi, S.M., Frederick, E.C., Hawes, M.R., \& Nigg, B.M. (1986). Influence of shoe} construction on lower extremity kinematics and load during lateral movements in tennis. International Journal of Sport Biomechanics, 2, 166-174.

21. Majewski, M., Susanne, H., \& Klaus, S. (2006). Epidemiology of athletic knee injuries: A 10-year study. The knee, 13, 184-188.

22. Nunley, R.M., Wright, D., Renner, J.B., Yu, B., \& Garrett Jr, W.E. (2003). Gender comparison of patellar tendon tibial shaft angle with weight bearing. Research in Sports Medicine, 11, 173-185.

23. Øiestad, B.E., Engebretsen, L., Storheim, K., \& Risberg, M.A. (2009). Knee osteoarthritis after anterior cruciate ligament injury a systematic review. The American Journal of Sports Medicine, 37, 1434-1443.

24. Olsen, O. E., Myklebust, G., Engebretsen, L., \& Bahr, R. (2004). Injury mechanisms for anterior cruciate ligament injuries in team handball a systematic video analysis. The American journal of sports medicine, 32, 1002-1012.

25. Roos, H., Adalberth, T., Dahlberg, L., \& Lohmander, L. S. (1995). Osteoarthritis of the knee after injury to the anterior cruciate ligament or meniscus: the influence of time and age. Osteoarthritis and Cartilage, 3, 261-267.

26. Severn, K.A., Fleming, P.R., Clarke, J.D., \& Carré, M.J. (2011). Science of synthetic turf surfaces: investigating traction behaviour. Proceedings of the Institution of 
Mechanical Engineers, Part P: Journal of Sports Engineering and Technology, 225, 147-158.

27. Shimokochi, Y., \& Shultz, S.J. (2008). Mechanisms of noncontact anterior cruciate ligament injury. Journal of Athletic Training, 43, 396-408.

28. Sinclair, J., Edmundson, C.J., Brooks, D., \& Hobbs, S.J. (2011). Evaluation of kinematic methods of identifying gait Events during running. International Journal of Sport Science \& Engineering, 5, 188-192.

29. Sinclair, J., Taylor, P.J., \& Hobbs, S.J. (2013). Alpha level adjustments for multiple dependent variable analyses and their applicability-a review. International Journal of Sport Science \& Engineering, 7, 17-20.

30. Sinclair, J. (2017). Effects of court specific and minimalist footwear on the biomechanics of a maximal 180 cutting manoeuvre. Human Movement, 18, 29-36.

31. Sinclair, J., \& Taylor, P.J. (2017). Effects of a prophylactic knee sleeve on anterior cruciate ligament loading during sport specific movements. Journal of Sport Rehabilitation (In press).

32. Smith, H.C., Vacek, P., Johnson, R.J., Slauterbeck, J.R., Hashemi, J., Shultz, S., \& Beynnon, B.D. (2012). Risk factors for anterior cruciate ligament injury: a review of the literature-part 1: neuromuscular and anatomic risk. Sports Health, 4, 69-78.

33. Stiles, V.H., \& Dixon, S.J. (2006). The influence of different playing surfaces on the biomechanics of a tennis running forehand foot plant. Journal of Applied Biomechanics, 22, 14-24.

34. Strauss, D., Messenger, N., Utley, A., \& Miller, S. (2009). Tennis footwear: An investigation of impact characteristics. Footwear Science, 1, 52-53. 
35. Thomson, A., Whiteley, R., \& Bleakley, C. (2015). Higher shoe-surface interaction is associated with doubling of lower extremity injury risk in football codes: a systematic review and meta-analysis. British Journal of Sports Medicine, 49, 1245-1252.

36. Valiant, G.A., McGuirk, T., McMahon, T.A., \& Frederick, E.C. (1985). Static friction characteristics of cleated outsole samples. Medicine \& Science in Sports \& Exercise, 17, 156-159.

37. Wannop, J.W., Luo, G., \& Stefanyshyn, D. (2009). Traction properties of footwear in Canadian high school football. Footwear Science, 1, 121-127.

38. Wannop, J.W., \& Stefanyshyn, D.J. (2016). The effect of translational and rotational traction on lower extremity joint loading. Journal of Sports Sciences, 34, 613-620.

\section{List of figures}

Figure 1: Experimental footwear upper and outsoles (a. = court footwear upper, b. = court footwear outsole, c. = running footwear d. = running footwear outsole).

Figure 2: ACL force as a function of different footwear (black = court footwear, grey = running footwear). 


\begin{tabular}{|c|c|c|c|c|c|c|}
\cline { 2 - 7 } \multicolumn{1}{c|}{} & \multicolumn{4}{c|}{ Court } & \multicolumn{3}{c|}{ Running footwear } \\
\cline { 2 - 8 } \multicolumn{1}{c|}{} & Mean & SD & $\mathbf{9 5 \%} \mathbf{C l}$ & Mean & SD & $\mathbf{9 5 \%} \mathbf{C l}$ \\
\hline Peak ACL load (N) & 2308.35 & 380.01 & $2036.51-2580.20$ & 1859.21 & 395.80 & $1576.07-2142.34$ \\
\hline Time to peak ACL force (ms) & 48.20 & 14.74 & $37.70-58.78$ & 49.80 & 13.81 & $39.88-59.65$ \\
\hline ACL average load rate (N/s) & 54295.37 & 12832.58 & $45115.49-63475.24$ & 42930.23 & 10059.78 & $35733.89-50126.56$ \\
\hline ACL instantaneous load rate (N/s) & 147762.11 & 41376.27 & $118163.31-177360.91$ & 103200.24 & 24934.95 & $85362.85-121037.63$ \\
\hline ACL impulse (N·s) & 330.14 & 87.71 & $267.40-392.89$ & 312.25 & 65.62 & $265.32-359.19$ \\
\hline
\end{tabular}

\begin{tabular}{|c|c|c|c|c|c|c|}
\cline { 2 - 7 } \multicolumn{1}{c|}{} & \multicolumn{4}{c|}{ Court } & \multicolumn{3}{c|}{ Running footwear } \\
\cline { 2 - 7 } \multicolumn{1}{c|}{} & Mean & SD & $\mathbf{9 5 \%}$ Cl & Mean & SD & $95 \%$ Cl \\
\hline Peak rotational moment $(\mathbf{N m})$ & 24.63 & 7.25 & $17.39-29.71$ & 19.56 & 6.52 & $14.49-23.91$ \\
\hline Peak translational coefficient of friction $(\boldsymbol{\mu})$ & 0.57 & 0.07 & $0.53-0.63$ & 0.64 & 0.08 & $0.58-0.70$ \\
\hline
\end{tabular}

